Wernicke B., Lidelöw H., and Stehn L. (2017). "Flow and Resource Efficiency Measurement Method in Offsite Production.” In: LC3 2017 Volume II - Proceedings of the 25th Annual Conference of the International Group for Lean Construction (IGLC), Walsh, K., Sacks, R., Brilakis, I. (eds.), Heraklion, Greece, pp. 861-

868. DOI: https://doi.org/10.24928/2017/0094

\title{
FLOW AND RESOURCE EFFICIENCY MEASUREMENT METHOD IN OFF-SITE PRODUCTION
}

\author{
Brian Wernicke ${ }^{1}$, Helena Lidelöw ${ }^{2}$, and Lars Stehn ${ }^{3}$
}

\begin{abstract}
Although the focus remains primarily on high resource efficiency, the significance of flow efficiency in construction is continuously increasing. Flow and resource efficiency describe two competing target viewpoints, which focus on reducing non-value adding activities and maximizing resource utilization, respectively. Recent research has shown that balancing both perspectives provides a viable solution. However, the exact measurement of flow and resource efficiency in construction remains unclear. Therefore, the aim of this work is to evaluate a possible flow and resource efficiency measurement method in the off-site production context of volumetric element construction, and assess the industrial relevance thereof. Work sampling has been used to collect data from a building project flowing through the off-site production system. The validity of the method has been checked statistically, through a focus-group workshop and with calculation figures from the case company. Work sampling allows flow and resource efficiency measurements in an off-site production system. The method delivers current status figures of companies, yielding a balance between flow and resource efficiency.
\end{abstract}

Keywords: House building, Industrialized construction, Performance measurement, Volumetric element, Work sampling.

\section{INTRODUCTION}

Traditionally, construction companies have tried to minimize production costs by maximizing their resource utilization, which represents a rational approach to using resources as efficiently as possible. However, to satisfy customers and stakeholders, factors (such as customer value, high delivery performance, short delivery times, or low tied-up capital) must be considered, which may contradict a strict resource efficiency focus. The flow efficiency approach focuses on the creation of a consistent flow from the customer order stage to the delivery stage. Companies, such as Toyota, have managed this by operating in accordance with the Lean philosophy (Liker 2004; Womack et al. 1990).

Industrialized construction companies try to improve their processes by working with platforms (Robertson and Ulrich 1998), where known technical solutions, manufacturing processes, cooperation agreements, and knowledge are preserved and repeated between projects. A successful platform addresses both resource and flow efficiency perspectives. If both approaches are essential, can they be combined in an off-site production context of industrialized construction? This work seeks to address that gap, by evaluating a possible flow and resource efficiency measurement method in the off-site production context of volumetric element construction, and assessing the industrial relevance thereof.

1 PhD student, Dept. of Civil, Envir. and Natural Resources Engrg., Div. of Industrialized and Sustainable Construction, Luleå Univ. of Technology, Sweden, brian.wernicke@ltu.se

2 Associate Professor, Dept. of Civil, Envir. and Natural Resources Engrg., Div. of Industrialized and Sustainable Construction, Luleå Univ. of Technology, Sweden, helena.lidelow@ltu.se

3 Professor, Dept. of Civil, Envir. and Natural Resources Engrg., Div. of Industrialized and Sustainable Construction, Luleå Univ. of Technology, Sweden, lars.stehn@ltu.se 


\section{THEORETICAL FRAMEWORK}

\subsection{Resource efficiency}

Resource efficiency is the traditional form of efficiency and focuses on using resources in the best manner possible. This approach has formed the basis of industrial development in the previous two centuries and enabled a significant reduction in production costs. Resource efficiency or utilization rate measures the amount of resources we use in a certain time interval (Modig and Åhlström 2015). The utilization of process resources refers to the fraction of available time that the resources perform useful work (Slack et al. 2013). Furthermore, the utilization of a workstation may even refer to the fraction of time it is not idle for lack of parts. This includes the fraction of time the workstation is working on parts or has parts waiting and is unable to work on these parts, because of a machine failure, setup, or some other detractor (Hopp and Spearman 2008). Resource efficiency can be calculated as:

$$
\text { Resource efficiency }=\frac{\text { Usage of resource }}{\text { Available time interval }}
$$

The available time can be defined as the sum of the setup, maintenance, waiting, and processing times. The processing time will, in most cases, be the time the resource adds value (Koskela 1992) to a flow unit and can be considered the time required for transformation of the work (Modig and Åhlström 2015).

\subsection{Flow efficiency}

Production refers to the flow of material and/or information from the raw-material stage to the end-product stage. The production flow can be described by the cycle time, which refers to the time required for a piece of material to traverse the flow. The cycle time, flow time, or throughput time, is the average time from the release of a job at the beginning of the flow to arrival of the job at an inventory point at the end (Hopp and Spearman 2008). The cycle time may even refer to the frequency with which a process completes a part or product (Rother and Shook 2009). Therefore, the authors will use the throughput time to express the time required for a piece of material to traverse the flow. During this flow, the material is processed (converted), inspected, waiting or moving. Processing represents the conversion aspect of production; inspecting, moving, and waiting represent the flow aspect (Koskela 1992). Obtaining a single unit of flow is essential for flow efficient operations (Simu and Lidelöw 2014). The flow efficiency is defined as the sum of times a flow unit receives value from the resources divided by the throughput time (Jones and Womack 2002; Modig and Åhlström 2015), and in this work is defined as:

$$
\text { Flow Efficiency }=\frac{\sum \text { Value-adding times }}{\text { Throughput time }}
$$

\subsection{Balancing resource and flow efficiency}

Resource and flow efficiency both measure value transfer from the resources to the flow unit, albeit from different viewpoints. While the resource perspective focuses on maximizing the value added by the resources (high resource utilization), flow efficiency refers to the degree of value received from the flow unit perspective (Modig and Åhlström 2015). The resource perspective drives companies toward production cost minimization, whereas the flow perspective pushes companies toward a customer-value focus, short delivery times, and reduced inventory. These perspectives should either be combined 
(Modig and Åhlström 2015) or balanced (Wernicke and Lidelöw 2016). This study is theoretically based in operations management. It is an operational principle, that process flow objectives should include interrelated parameters such as the throughput rate, throughput time, work-in-progress, and resource utilization (Slack et al. 2013).

\section{RESEARCH DESIGN}

\subsection{The case}

A single case study was performed with a medium-size construction contractor, producing multi-storey buildings using prefabricated volumetric elements delivered from the company's off-site production system. This system can roughly be described as four planar element production lines for floors, walls and ceilings, one volumetric element assembly line, three parallel final assembly lines (for completion of electricity, pipes, tiles, wall paints, wardrobes, bathroom, and kitchen interior), and a wrapping line. The production lines are divided into workstations. In this study, the flow unit consists of planar floor elements before and volumetric elements after the volumetric element assembly. The flow units move through all lines, in accordance with the "first in first out" principle. The resources of the study are the operators who process the flow units on the workstations, without being permanently linked to a workstation. These operators move between different workstations and are organized in different teams depending on the volume of work and the corresponding tasks (e.g., assembly, electricity, piping, and final inspection), respectively.

Lean has been influencing the company since 2006 and became the foundation of the company's philosophy in 2010. The company is a Lean-award winning organization and is known as a strong performer in that field. Flow-related questions have increased in recent years and many ideas and improvements have been tested, but a method for quantifying the complex effects on the production system remains elusive. Production proceedings and operator times spent in production are reported daily. The company's calculation system delivers estimated figures for operator work load planning on a project basis. However, resource or flow efficiency cannot be calculated from the available data.

\subsection{Data collection method}

The study was limited to a project consisting of two buildings with eight apartments each, prefabricated as 42 volumetric elements in the company's off-site production system. Data collection in this system was limited to the following observation zone: floor line (five workstations), volumetric element assembly line (four workstations), all three final assembly lines (44 workstations), and a safety stock between the floor and the assembly line. The following had to be accounted for during the design of the data collection method: (i) the size of the project and the observation zone and (ii) at a certain time during collection, all 42 flow units could be located inside the observation zone.

According to Freivalds and Niebel (2009), work sampling is effective for determining personnel utilization and production standards, yielding the same information as time studies, but requires less time and is considerably more cost-effective. Work sampling, a statistical technique for work studies, is based on the law of probability, where random objects are studied at fixed time intervals or fixed object sequences are studied at random time intervals (Almström and Kinnander 2011). For this study, the workstations and the safety stock were designated as the fixed objects, while the flow units and the operators were defined as random objects. Compared to time studies, data collection via work 
sampling is based on momentary observations, without the intention of observing all the activities. The results are derived from several observations with the time interval as a steering parameter for the number of evaluable observations.

In this study, the time interval between the observations ( $\sim 15 \mathrm{~min})$ is considered random due to observer breaks, unsteady time for the observation cycles through the observation zone, and the difference between observation and production times. The observations (for 11 days between ca. 7:30 am and 4:00 pm) begin with the production start of the first flow unit and lasts until the last flow unit leaves the observation zone. Production occurs in three different shifts from 5:45 am to 1:00 am, with most operators working between 7 am and $4 \mathrm{pm}$. With more than 20 flow units in the observation zone, the number of observers is increased to ensure an observation cycle of $\sim 15 \mathrm{~min}$. On those days, the observation zone is divided among three observers, with the intention that they are all able to observe their allocated part within a measurement cycle time of $15 \mathrm{~min}$. The results of the observations are either directly input into an Excel spreadsheet or first notated on paper spreadsheets, following the flow units, before transmission (by the observers) to the Excel spreadsheet.

Each observation yields a data notation consisting of the date, time, observer, flow unit number, workstation or stock, number of operators inside or around the flow unit, and an operator activity classification. The activities are simplified, i.e., all operators are considered busy with activities that are classified as follows: a) value-adding activities or processing tasks with direct value transfer from operators to a flow unit, b) supporting activities e.g., planning, material handling, cleaning, maintenance or setup, c) waiting including disturbance and personal time, and d) unclear for the observer. The classification is further used in table 2. The details provided are obtained from measuring the group, rather than individual workers.

\subsection{Data analysis method}

To enable data analysis supplementary to both the overall project and individual flow unit levels, all flow units are divided into six similarly designed flow unit types (table 1). The case study is analyzed using an Excel database. Equations 1 and 2 are modified for applicability to the case data, and are therefore based on time units, rather than discrete numbers. Jones and Womack (2002) employed the particular value-creating steps and related them to the total number of supply chain steps. Therefore, the flow efficiency is redefined as:

$$
\text { Flow Efficiency }=\frac{\sum \text { Value-adding flow unit type observations }}{\sum \text { Flow unit type observations }} \%
$$

The observed operator activity categories are used to describe resource utilization. All value-adding and supporting activities are labelled as utilization, whereas waiting and unclear activities are not and, hence, the resource efficiency is redefined as:

$$
\text { Resource efficiency }=\frac{\sum \text { Value-adding }+ \text { Supporting operator activities }}{\sum \text { Operator activities }} \%
$$

\section{EMPIRICAL FINDINGS}

The empirical results obtained from the Excel database are used to calculate the flow and resource efficiency. Table 1 shows the observation data aggregated at the flow unit type level. Each flow unit observation contains a discrete number of operators ranging from 
zero to seven. The observed activities per flow unit type and for the overall project are shown in table 2 .

Table 1: Number of flow unit observations from a 15-min observation cycle.

\begin{tabular}{ccccccc}
\hline Flow unit type & $\begin{array}{c}\text { Kitchen } \\
\text { \& Bath } \\
\text { type 1 }\end{array}$ & $\begin{array}{c}\text { Kitchen } \\
\text { \& Bath } \\
\text { type 2 }\end{array}$ & $\begin{array}{c}\text { Two } \\
\text { Bed- } \\
\text { rooms }\end{array}$ & $\begin{array}{c}\text { Stair- } \\
\text { well }\end{array}$ & $\begin{array}{c}\text { Living } \\
\text { room }\end{array}$ & $\begin{array}{c}\text { Living \& } \\
\text { Bed- } \\
\text { room }\end{array}$ \\
\hline Number in project & 8 & 8 & 6 & 4 & 6 & 10 \\
Number of observations & 1069 & 1070 & 799 & 536 & 776 & 1310 \\
$\begin{array}{c}\text { Number of value-adding } \\
\text { observations }\end{array}$ & 501 & 512 & 249 & 119 & 147 & 369 \\
\hline
\end{tabular}

Table 2: Number of categorized operator activities (see section 3.2).

\begin{tabular}{ccccccccc}
\hline $\begin{array}{c}\text { Flow unit } \\
\text { type }\end{array}$ & $\begin{array}{c}\text { Kitchen } \\
\text { \& Bath } \\
\text { type 1 }\end{array}$ & $\begin{array}{c}\text { Kitchen } \\
\text { \& Bath } \\
\text { type 2 }\end{array}$ & $\begin{array}{c}\text { Two } \\
\text { Bed- } \\
\text { rooms }\end{array}$ & $\begin{array}{c}\text { Stair- } \\
\text { well }\end{array}$ & $\begin{array}{c}\text { Living } \\
\text { room }\end{array}$ & $\begin{array}{c}\text { Living\& } \\
\text { Bed- } \\
\text { room }\end{array}$ & $\begin{array}{c}\text { Total } \\
\text { project } \\
\text { (No.) }\end{array}$ & $\begin{array}{c}\text { Total } \\
\text { project } \\
\text { (\%) }\end{array}$ \\
\hline $\begin{array}{c}\text { Value- } \\
\text { adding }\end{array}$ & 822 & 919 & 397 & 196 & 224 & 591 & 3149 & 64 \\
$\begin{array}{c}\text { Supporting } \\
\text { Waiting }\end{array}$ & 347 & 241 & 165 & 99 & 95 & 229 & 1176 & 24 \\
Unclear & 141 & 152 & 50 & 59 & 15 & 65 & 482 & 10 \\
\hline
\end{tabular}

\section{ANALYSIS \& DISCUSSION}

Using the data from tables 1 and 2 and equations 3 and 4, flow and resource efficiency (see figure 1) can be calculated on the flow unit type level. This figure shows the number of observations (in terms of a percentage) with at least one operator that adds value to the flow unit type. For example, the living room accounts for $19 \%$ of the observations. This is realized by the operators who can be described by the resource efficiency, e.g., $94 \%$ of the operators perform value-adding or supporting activities when attendant to the living room. According to the operational principle, the process flow objectives should include interrelated parameters such as the throughput rate, throughput time, work-in-progress, and resource utilization (Slack et al. 2013). Therefore, the flow efficiency of a flow unit type is realized through a certain set, and use, of resources. 


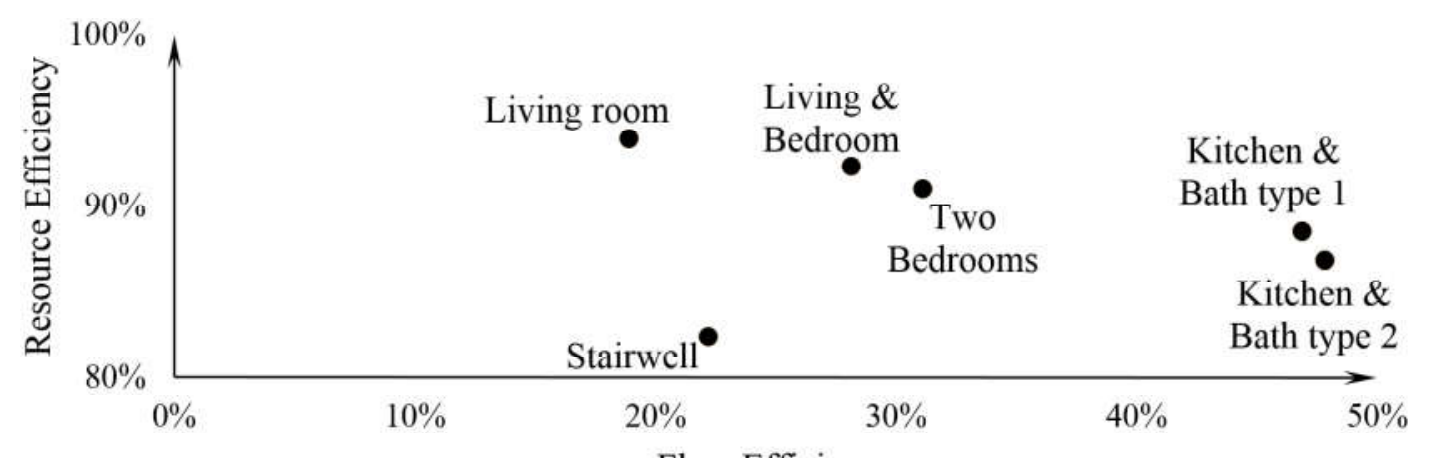

Flow Efficiency

Figure 1: Flow and resource efficiency per flow unit type.

The combined visualization of flow and resource efficiency has been discussed by Modig and Åhlström (2015). They describe the difficulty organizations face in increasing their flow efficiency, while focusing mainly on high resource efficiency, and the possibility of simultaneously achieving high flow and resource efficiency. Furthermore, according to these authors, the potential for maximizing both types of efficiencies is affected by variations in the flow unit. Figure 1 shows that, except for the stairwell, the flow unit types with the highest flow efficiency (Kitchen \& Bath) have relatively low resource efficiency. This may have resulted from the fact that this flow unit type (i.e., the stairwell) accounts for the lowest number of flow units and observations in the dataset. Therefore, the corresponding statistical uncertainty is higher than that associated with the other flow unit types. However, the figures enable discussion of the differences in the flow of the units through the off-site production system, effect of flow unit type variation on the involved resources, and potential operational strategies for managing both.

\subsection{External validity}

A workshop together with two production managers (one first line manager, one head of production management) from the case company has been completed to discuss the figures. The first line production manager pointed out that visualizing flow and resource efficiency in one diagram is quite challenging, because (i) on the one hand, meeting requests of meeting flow efficiency targets as short throughput time or takt and (ii) resource efficiency targets as minimizing operator times spent on the other hand. The fact that competitive targets occur represents the generalizable part of this study. Although the figures are case specific, the methodology can be applied to other cases.

\subsection{Internal validity}

The validity of using work sampling as a method is debatable (Kalsaas 2011). For example, the observers review only a part of the observation zone and the observations are accidental. In the present study, an observation interval of $\sim 15$ min yields 5560 single observation points, creating a consistent dataset that enables correlation between the discrete number of observations and the time units associated with throughput and activities. An average of 132 observations with a standard deviation of 6.4 per flow unit is obtained. The number of observations and its even deviation create a stable base for calculating the flow unit or flow unit type level. Owing to the targeted observation interval, the number of observers had to be increased to ensure a stable high-quality observation cycle, when the project accounted for more than half of the observation zone. However, the internal validity is negatively affected by the increasing number of observers. The first author of the article was the main observer and was always present at the case company 
during the observations. Depending on the number of objects in the flow, additional observers were present at the final assembly lines. They were introduced by the main observer with prepared examples and a test notation run prior to the real observations. Between the observation cycles, the observers discussed the encountered scenarios and possible methods for notating hesitant observations. The number of unclear observations (table 2) is considered a quality indicator of the measurement method. A significant share could be interpreted as unsure observers or a method uncertainty, but the figure has been on a low level with $\sim 2 \%$.

To further validate the measurement method, the observed number of operators per flow unit type is compared with the estimated figures for operator work load, as determined via the company's calculation system (figure 2). Both data series equals $100 \%$ each. The company's calculation system classifies the work load in terms of the different flow unit types, whereas the data denoted as observed correspond to the total number of operator activities shown in table 2. The level of uncertainty of the estimated figures stems from equal distribution, among the flow unit types, of some of the tasks associated with the operator work load. In addition, some of the tasks were excluded and the production managers (head of production management) explained that the company's calculation system is only sometimes updated with the current figures corresponding to the production activities. Nevertheless, the comparison indicates that the results of the measurement method and the estimated figures are correlated and enables an evaluation of the company's calculation figures.

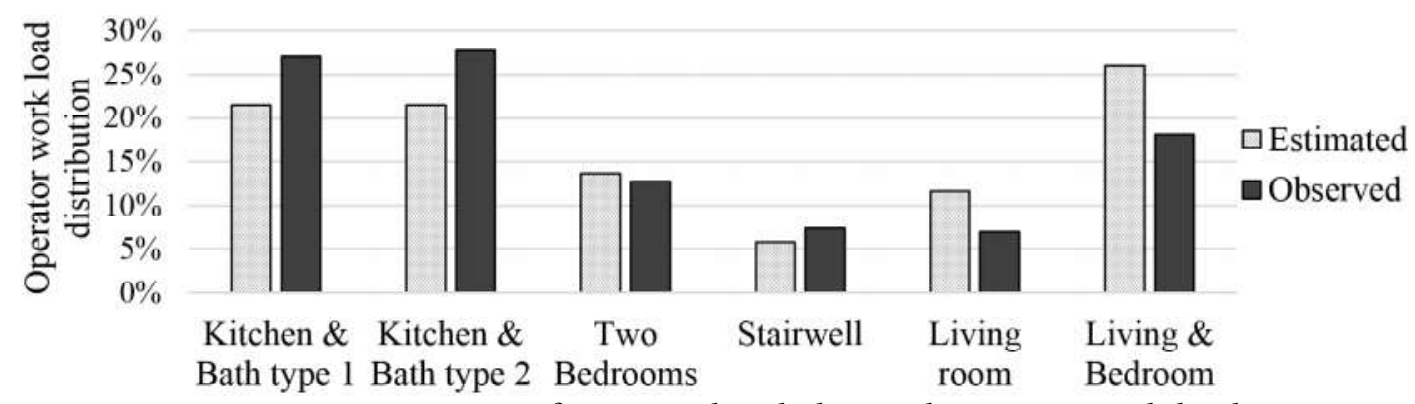

Figure 2: Comparison of estimated and observed operator work load.

\section{CONCLUSION}

Combined measurements of flow and resource efficiency are possible in the off-site production context of volumetric element construction, and work sampling can be used as a data collection method. The results indicate that discrete observations are correlated with the physical production flow for the chosen observation interval, but work sampling remains a time consuming method for the observation object considered. The question of balancing flow and resource efficiency is an important issue for the case company. Strategic targets of improving flow (expressed by takt or reduced throughput time) meet operational goals of using minimum resources (expressed as operator times spent).

\section{FUTURE RESEARCH}

The measurement method has the potential to help companies with their decision making process by showing the current status figures of how companies balance flow and resource efficiency. This method should be evaluated in different case companies and contexts, e.g., 
during on-site production. Moreover, the validity thereof could be determined via statistical methods that answer legitimate questions (such as required observation interval, demand for time interval stability, and the measurement method confidence interval).

\section{ACKNOWLEDGMENTS}

The authors gratefully acknowledge the financial support of TräCentrum Norr through the European Regional Development Fund. Furthermore, the company representatives are gratefully acknowledged for their time, openness, and insights.

\section{REFERENCES}

Almström, P. and Kinnander, A. (2011). The productivity potential assessment method, International Journal of Productivity and Performance Management, 60(7), 758-770.

Hopp, W.J. and Spearman, M.L. (2008). Factory physics. (International 3. ed.), McGrawHill Publishing, Boston.

Jones, D.T. \& Womack, J.P. (2002). Seeing the whole: mapping the extended value stream. Brookline, MA.: Lean Enterprise Inst.

Kalsaas, B.T. (2011). On the discourse of measuring work flow efficiency in construction. A detailed work sampling method. 19th Annual Conference of the International Group for Lean Construction (IGLC).

Koskela, L. (1992). Application of the new production philosophy to construction. Technical report number 72. Stanford University.

Liker, J.K. (2004). The Toyota way: 14 management principles from the world's greatest manufacturer. McGraw-Hill, New York.

Modig, N. \& Åhlström, P. (2015). This is lean: resolving the efficiency paradox. Stockholm: Rheologica publishing.

Freivalds, A. \& Niebel, B.W. (2009). Niebel's Methods, standards, and work design. (12. ed.) New York: McGraw-Hill Higher Education.

Robertson, D. and Ulrich, K. (1998). Planning for product platforms. Sloan Management Review, 39(4), 19-31.

Rother, M. \& Shook, J. (2009[1999]). Learning to see: value stream mapping to create value and eliminate muda. Cambridge, Mass.: Lean Enterprise Institute.

Simu K. and Lidelöw H. (2014). The effect of economic variation in construction projects on contractor firms. 22nd Annual Conference of the International Group for Lean Construction (IGLC).

Slack, N., Brandon-Jones, A. \& Johnston, R. (2013). Operations management. (7. ed.) Harlow: Pearson.

Wernicke, B. and Lidelöw H. (2016). Foundation for Balancing Resource and Flow Efficiency in Industrialized Construction. ICCREM 2016 - International Conference on Construction \& Real Estate Management.

Womack, J.P., Jones, D.T. and Roos, D. (1990). The machine that changed the world. Rawson Associates, New York. 